\title{
Fault Modeling and Simulation of Aviation Engine Fuel Return Valve
}

\author{
Wang Liwen ${ }^{1,2,3,{ }^{*}}$, Zhang $\mathrm{Lu}^{1}$ and Shi Xudong ${ }^{2,3}$ \\ ${ }^{1}$ School of Mechanical Engineering, Tianjin University, Tianjin, China \\ ${ }^{2}$ Ground Support Equipments Research Base, Civil Aviation University of China, Tianjin, China \\ ${ }^{3}$ Aeronautical Automation College, Civil Aviation University of China, Tianjin, China
}

\begin{abstract}
Fuel return valve is an important part of aviation engines. It achieves the cooling of integrated drive generator by regulating the amount of fuel in the oil cooler of integrated drive generator. Fault modeling and simulation of fuel return valve can provide targeted guidance for its maintenance. This paper establishes fuel return valve's mathematical model which includes the flow control valve, the electromagnetic valves and other components. The model is simulated using Simulink, and the effects sub-component failure takes on the fuel return valve in flow and transient characteristics are analyzed, which can provide a theoretical support for its maintenance.
\end{abstract}

Keywords: Aero Engine, Failure Analysis, Fuel Return Valve, Modeling, Simulink Simulation.

\section{INTRODUCTION}

In aero-engines, the cooling of integrated drive generator (IDG) mainly relies on fuel return valve (FRV). Engine fuel system turns the hot fuel in oil cooler back to aircraft's fuel tank, and lets the cold fuel flow into the oil cooler to ensure the cooling of IDG. The FRV achieves the regulation on IDG cooling by controlling the amount of fuel flows into the IDG oil cooler. In order to prevent the temperature of fuel which returns to the fuel tank too high, the FRV lets the cold fuel from the low pressure fuel pump and the hot fuel oil from IDG oil cooler mixed, reducing the temperature of the fuel, which makes temperature of mixed fuel back to fuel tank in a safe range. Electronic control unit controls the FRV according to the engine oil temperature of IDG. In different flight state and engine oil temperature, electronic control unit makes the FRV in a different operating state to ensure the safe and reliable operation. If the FRV fails, it will cause failure or damage of IDG, so the analysis of fault diagnosis of the FRV is of great importance.

In recent years, several methods for analyzing aircraft fuel fault are established: Firstly, fault tree and expert system based on knowledge [1-3]; Secondly, modeling and simulation of the physical model, such as using the Flow master fluid simulation software which is a useful way to diagnose the FRV faults [4- 6]; Thirdly, transfer function analysis of the classical control theory [4] and; Finally, the health status is monitored for fault analysis [7-10]. With the help of Simulink, we studied the function of each element by establishing their models respectively and the FRV's simulation model is established on this basis. Then, the impact each component's failure which takes on the total fault output of the

*Address correspondence to this author at the Aeronautical Automation College, Civil Aviation University of China, Tianjin, China;

E-mail: fighting088@126.com
FRV is studied, and the transient and steady-state characteristics are analyzed.

\section{FUEL RETURN VALVE WORKING PRINCIPLE}

The FRV is composed of V1, V2 solenoids, hi/low flow valve, flow control valve, shut off valve and some orifices. $\mathrm{V} 1, \mathrm{~V} 2$ solenoids receiving signals from the electronic control unit, control the fuel return valve in which operating state. Fuel shutoff valve has three operating states, namely zero-flow mode, low-flow mode and high-flow mode. When the solenoids are not energized, the FRV is in the closed state, at zero-flow mode; when only the V1 solenoid is energized, the fuel return valve in the low-flow mode lets fuel returned back to fuel tank at a flow rate which is about $500 \mathrm{KGH}$; when both the V1 and V2 solenoids are energized, or only V2 is energized, the FRV is in a high flow mode and the total output flow rate is about $1000 \mathrm{KGH}$. The hi/low valve with different working condition of the FRV, is in the open or closed state.

The operation schematic diagram of the FRV is shown in Fig. (1). When shutoff valve is connected with the lowpressure bypass pressure $(\mathrm{Pb})$ fuel and V1 solenoid is energized, the high pressure fuel flow (PSF) slew opens the shut off valve (SOV). The hot low pressure fuel flow (HLP) and cold low pressure (CLP) fuel flow are mixed via a set of orifices according to 2:3 ratio. Then the mixed flow passes through flow control valve (FCV) and SOV and is returned to the fuel tank. As the HLP and CLP on the back side of the FCV get higher, the FCV piston is forced to stroke in the closed direction thus reducing the area of the FCV port. Conversely, as the reference pressure gets lower, the FCV piston is forced to stroke in the open direction thus increasing the area of FCV port. This allows the FCV to maintain a nearly constant differential pressure across a set of orifices upstream of the FCV. 


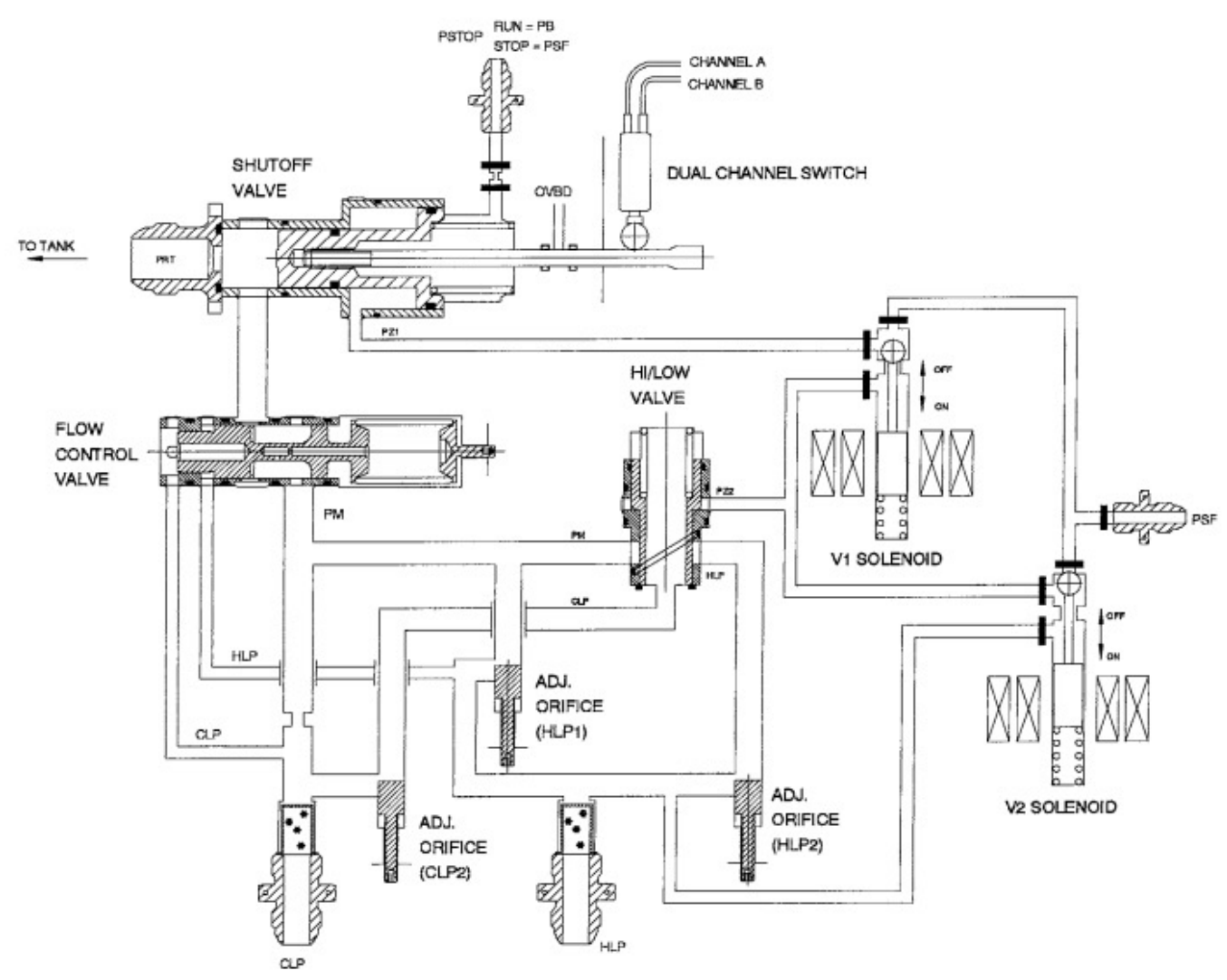

Fig. (1). Schematic diagram of operation.

When the V2 solenoid or both solenoids are energized, PSF is used to slew open the SOV. PSF is also used to slew open the hi/low valve allowing flow to pass through an additional set of orifices to FCV. At this time, the FRV switches from low flow mode to high flow mode.

\section{THE MATHEMATICAL MODELING OF FUEL RETURN VALVE}

First of all, we established mathematical elements of the FRV models respectively, and then established the total model according to the relationship between each element's input and output. The system block diagram of the FRV is shown in Fig. (2), where LO is a set of orifices activated in low flow mode, and HO is an additional set of orifices activated in high flow mode. The orifices and FCV on main fuel circuit mainly affect the static characteristics of the FRV' $s$ output flow, while the solenoids, SOV and hi/low valve on control flow circuit effect reaction time of the FRV. The mathematical models of main fuel circuit and control flow circuit are respectively established.

\subsection{The Establishment of the Main Fuel Circuit Model}

As the HLP and CLP have been mixed before passing through the FCV, the set of orifices can be regarded as one orifice. As the low flow mode switch to high flow mode, the flow is allowed to pass through an additional set of orifices to FCV, which can be seen as the increased orifice area. The flow rate through the orifice is:

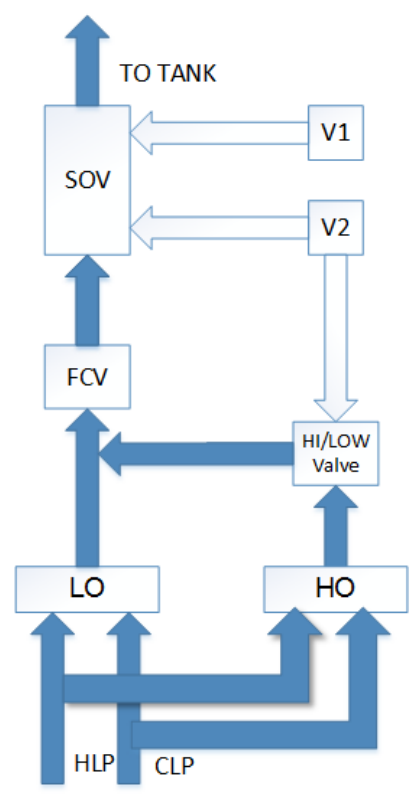

Fig. (2). Fuel return valve block diagram.

$Q_{1}=C A_{1} \sqrt{\frac{2}{\rho}\left(p_{0}-p_{M}\right)}$

In the formula: $C$ - flow coefficient; $A_{1}$ - flow area of the orifice; $p_{M}$ - pressure of the mixed fuel flow; $p_{0}$ - orifice inlet pressure; $\rho$ is the fuel density. The flow rate through the FCV is: 


$$
Q_{2}=C A_{2} \sqrt{\frac{2}{\rho}\left(p_{M}-p_{2}\right)}
$$

In the formula: $A_{2}(x)$ - is the flow area of the FCV whose port is an equilateral triangle. $A_{2}(x)=n\left(x_{1}-x\right)^{2}, x-$ is the spool displacement, $x_{1}$ - is the length of the port pre-opening. $p_{2}$ is the outlet pressure of the FCV. According to the principle of flow continuity and the pressure, loss is not calculated, the total flow rate:

$Q=Q_{1}=Q_{2}$

Without considering the elasticity and flow force of fuel, the force balancing equation of FCV piston is:

$$
p_{0} A-K\left(x_{0}+x\right)=m \frac{d^{2} x}{d t^{2}}+B \frac{d x}{d t}
$$

In the formula: $A$ - is the effective area of the FCV piston; $K$ - is the spring stiffness of the FCV; $x_{0}$ - is the spring pre compression; $m$ - is the the quality of the FCV piston and a part of spring; $B$ - is the the viscous damping coefficient of the FCV. After the (4) equation is transformed using Laplace transform, we got that:

$$
x=\frac{p_{0} A-K x_{0}}{m s^{2}+B s+K}
$$

Thus, the function of the FCV piston' displacement caused by $p_{0}$ changing is acquired. By solving formulas (1), (2) and (3), equation 6 can be obtained as follows:

$$
\frac{Q^{2} \rho}{2 C^{2}}\left(\frac{1}{K^{2}\left(x_{1}-x\right)}+\frac{1}{A_{1}^{2}}\right)=p_{0}-p_{2}
$$

$$
\text { Define } \frac{1}{K^{2}\left(x_{1}-x\right)}+\frac{1}{A_{1}^{2}}=\Delta \text {, Sort out the relation formu- }
$$

la between flow, inlet fuel pressure and outlet fuel pressure as follows:

$$
Q=\sqrt{\frac{2 C^{2}\left(p_{0}-p_{2}\right)}{\rho \Delta}}
$$

\subsection{The Establishment of the Control Flow Circuit Mod- el}

The control flow circuit is composed of solenoids, SOV and hi/low valve. The motion of solenoid's electromagnetic part can be obtained as a quadratic equation, while a linear equation exists between flow rate and displacement of the FCV piston [11].

The transfer function of the electromagnetic part can be expressed as:

$$
\frac{X_{m}(s)}{I(s)}=\frac{c_{1}}{s^{2}+a_{1} s+a_{2}}
$$

In the vicinity of the nominal operating point of the solenoid, the rate of flow through the valve body can be expressed as:

$$
Q \approx 38.034 c_{d} A_{0} \sqrt{\frac{\Delta p}{\rho}}
$$

In this formula, $Q$ - is the volume flow, $A_{0}$ - is the cavity area, $\Delta p$ - is the pressure drop through the cavity. The pressure drop through the cavity can be regulated at a constant speed, so the volume flow rate is proportional to the displacement of solenoid's spool.

$\delta Q \approx 38.034 c_{d}\left(\frac{\partial A_{0}}{\partial X_{m}}\right) \delta X_{m}=c_{2} \delta X_{m}$

Therefore, the relationship of the flow rate and the displacement of the solenoid can be represented by a gain constant, then the transfer function of solenoid can be expressed as:

$\frac{Q(s)}{I(s)}=K \frac{c_{1}}{s^{2}+a_{1} s+a_{2}}$

The SOV and hi/low valve are typical flow components. In case of without considering the hydraulic oil compression elastic, their transfer function is a quadratic equation [12].

$\frac{X(s)}{Q(s)}=\frac{c_{2} A_{p}}{M_{p} s^{2}+c_{2} A_{p} A_{d} s}$

In this formula, $c_{2}$ is the flow-pressure gain, $A_{p}$ is acting area, $A_{d}$ is the fluid damping, $M_{p}$ is the spool quality.

The formula (1) shows that under the condition if the pressure is invariable, the flow rate is proportional to the flow area. The effect of the SOV's piston displacement on the total fuel flow can be represented as:

$Q^{\prime}=C \frac{A(x)}{A_{0}} Q$

In the formula, $Q^{\prime}$ is the flow rate that actually flows through, $A_{0}$ is the flow area when SOV is full open, $A(x)$ is a function that SOV flow area changes with the spool displacement:

When the spool displacement $x<\frac{D}{2}, D$ is the diameter of orifice,

$$
\begin{aligned}
& A(x)=\frac{\pi D^{2}}{2 \cdot 360^{\circ}} \arcsin \frac{2 \sqrt{D x-x^{2}}}{D} \\
& -\left(\frac{D}{2}-x\right) \sqrt{D x-x^{2}}
\end{aligned}
$$

When the spool displacement $x \geq \frac{D}{2}$, set $x^{\prime}=D-x$,

$$
\begin{aligned}
& A(x)=\frac{\pi D^{2}}{2}-\frac{\pi D^{2}}{2 \cdot 360^{\circ}} \arcsin \frac{2 \sqrt{D x^{\prime}-x^{\prime 2}}}{D} \\
& +\left(\frac{D}{2}-x^{\prime}\right) \sqrt{D x^{\prime}-x^{\prime 2}}
\end{aligned}
$$




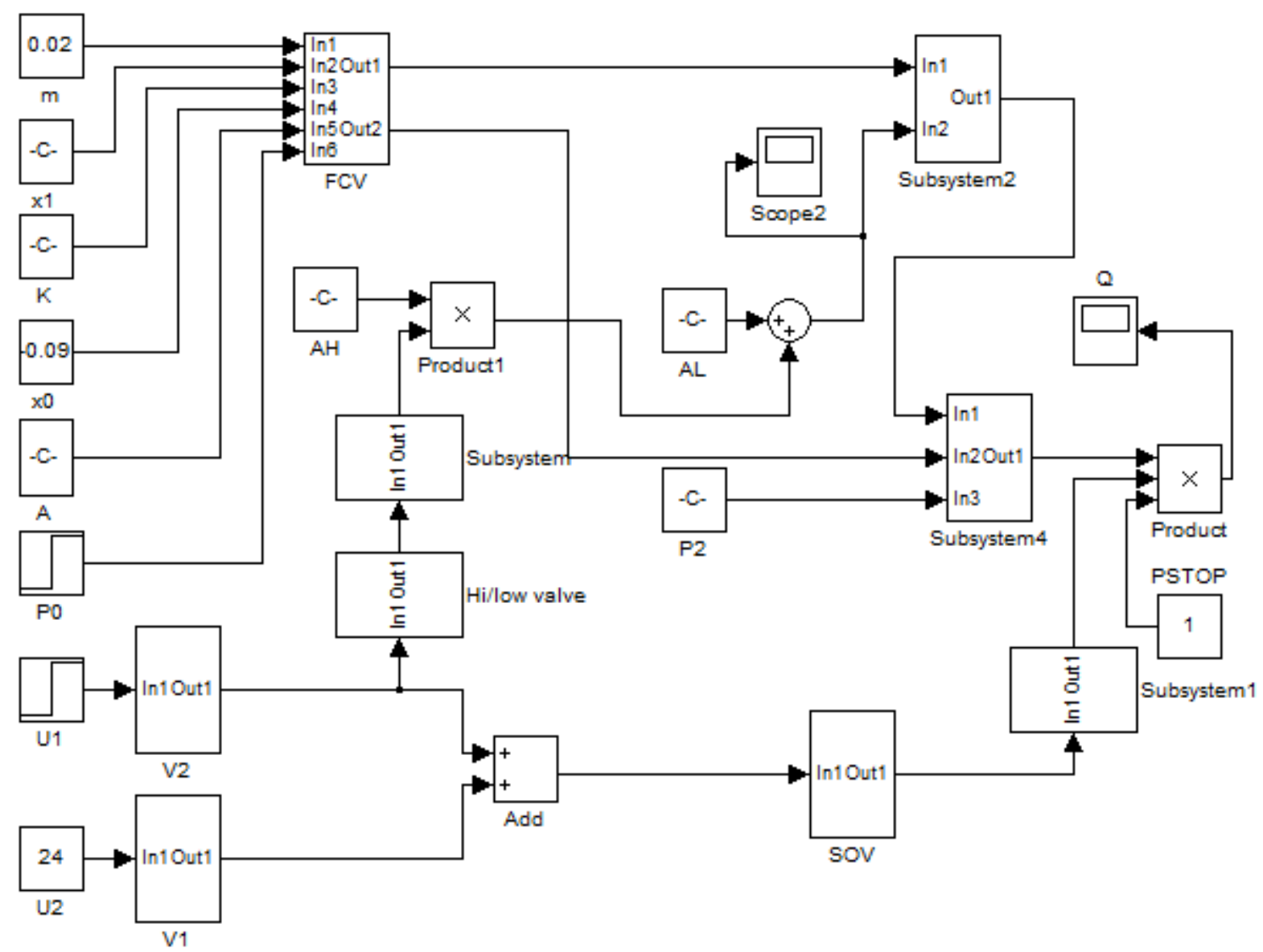

Fig. (3). Simulation structure diagram.

When hi/low valve is opened, the by-pass orifices opened equivalent to the orifice's area are increased. Set the orifice's area as $A_{L}=A_{L}+A_{H}$, where $A_{L}$ is a fixed flow area of orifice when low flow mode is operating; $A_{H}$ is additional by-pass area of orifice in high flow mode. When switch to the high flow mode, along with the hi/low flow valve slewing open, the orifice's area will change, the change of $A_{H}$ with reference to formula(13) is:

$A_{H}=C \frac{A^{\prime}(x)}{A_{0}^{\prime}} A_{H 0}$

In the formula, $A_{H 0}$ is the largest area of by-pass orifice. $A^{\prime}(x)$ is the flow area of hi/low valve, which changes with the variation of spool displacement. $A^{\prime}{ }_{0}$ is the maximum flow area, whose function formula is same as the (14) and (15) formulas.

Combined with the flow rate formula (7) of main fuel circuit and the formula (13) of the control flow circuit, the actual fuel output flow rate $Q$ ' of the FRV can be expressed as:

$$
Q^{\prime}=\frac{A(x)}{A_{0}} \sqrt{\frac{2 C^{2}\left(p_{0}-p_{2}\right) A_{1}^{2} K^{2}\left(x_{1}-x\right)}{\rho\left(A_{1}^{2}+K^{2}\left(x_{1}-x\right)\right)}}
$$

\section{SIMULATION AND FAULT ANALYSIS}

According to the mathematical model, a simulation model is built up with Simulink as shown in Fig. (3), and then the established model is simulated. Fig. (4) shows the simulation of output flow switching from low flow model to high flow mode in operation. At the time $0 \mathrm{~s}$ V1 solenoid was energized, the FRV starts operating in low flow mode. Then, at the time when $5 \mathrm{~s}$ V2 solenoid was energized, the FRV is switched to operate in high flow mode. The fault performances of the FRV mainly include: the rate of fuel flow exceeding the standard, shutoff valve response time-out, the FRV refusing to move and the external leakage. The established computer simulation model is used to discuss the effect of each component's failure on the FRV, so as to help in analyzing the causes of the FRV failure.

\subsection{Simulation Analysis for the Fault of Flow Rate Ex- ceed the Standard}

The spring stiffness in FCV would change after long time service. Therefore, the impacts of different spring stiffness on traffic are considered. Fig. (5) shows the respective pressure flow characteristic curves when the spring stiffness were $10 \mathrm{~N} / \mathrm{mm}, 13 \mathrm{~N} / \mathrm{mm}, 16 \mathrm{~N} / \mathrm{mm}, 19 \mathrm{~N} / \mathrm{m}$ and $22 \mathrm{~N} / \mathrm{mm}$. As 


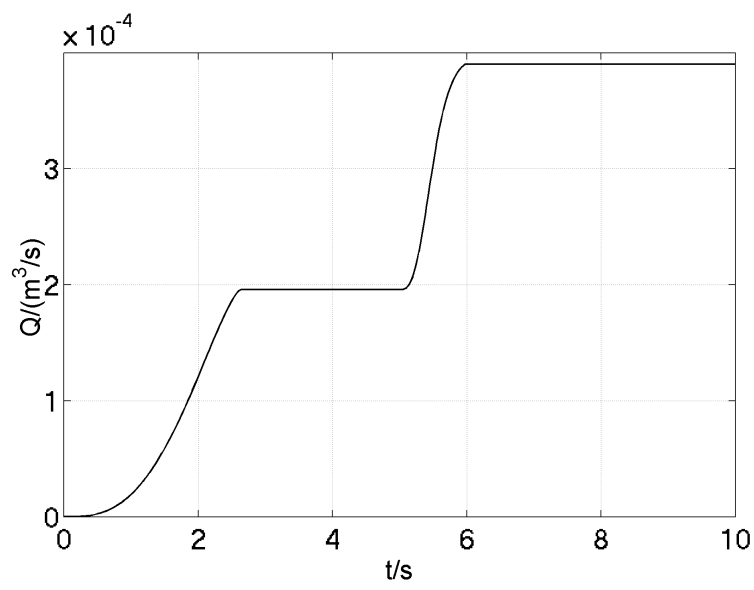

Fig. (4). Output simulation from low flow mode to high flow mode.

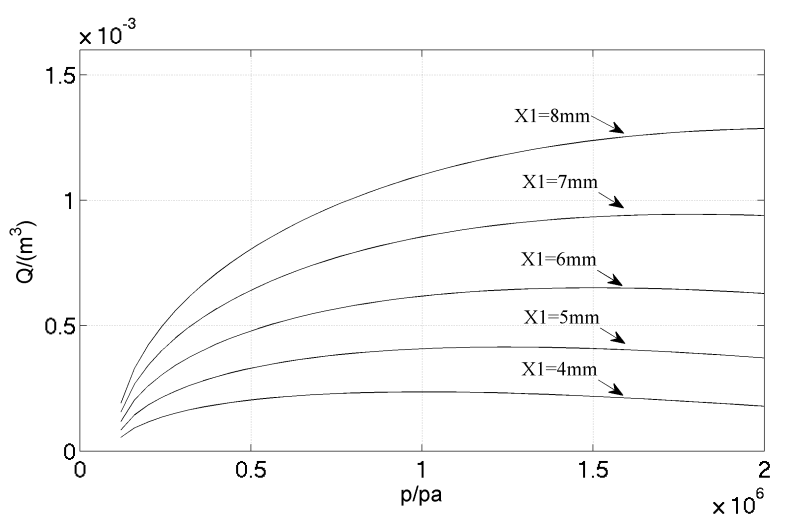

Fig. (5). Flow characteristic curves under different stiffness spring.

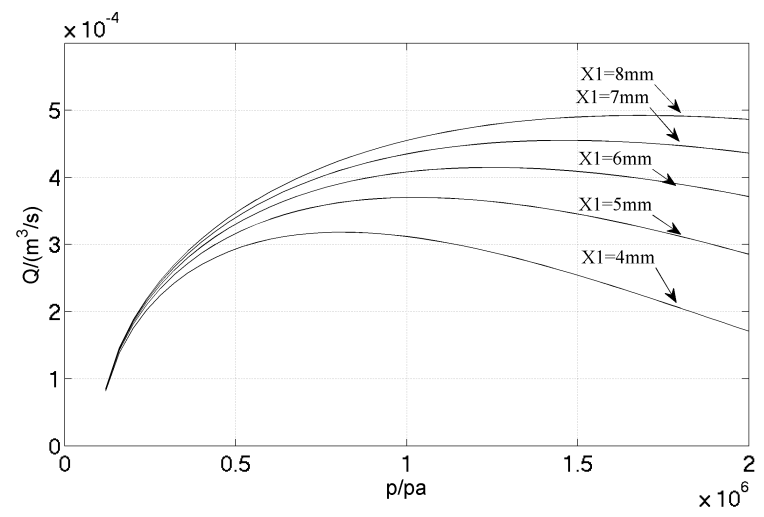

Fig. (6). The flow control valve flow characteristic curves under different spring pre-compression.

can be seen from the figure, spring stiffness variation has a significant effect on the rate of flow, at the same time the adaptability to the change of pressure is limited. The reason being, in order to make the structure compact, the oil passage linking the FCV piston ends to PM, was not designed. So, when the FCV piston is in a static balance status, it is only forced by spring and the p0 pressure. As equation (1) shows, the orifice flow can maintain a constant only when the differential pressure is $\mathrm{p} 0-\mathrm{pm}$, which is constant at the two ends of piston. Therefore, rate of flow through the FRV is effected by the fuel pressure and not by the constant. Because the
FRV inlet pressure's change range is not large, as long as the spring stiffness is maintained within a certain pressure range, the flow will maintain nearly at a constant rate.

Spring pre-compression will affect the FCV open pressure. Therefore, under the same pressure, different precompression of the FCV leads to different area of the FCV port. Fig. (6) shows the flow characteristic curves under different pre-compression where noticeable effect on the flow rate can be seen. 


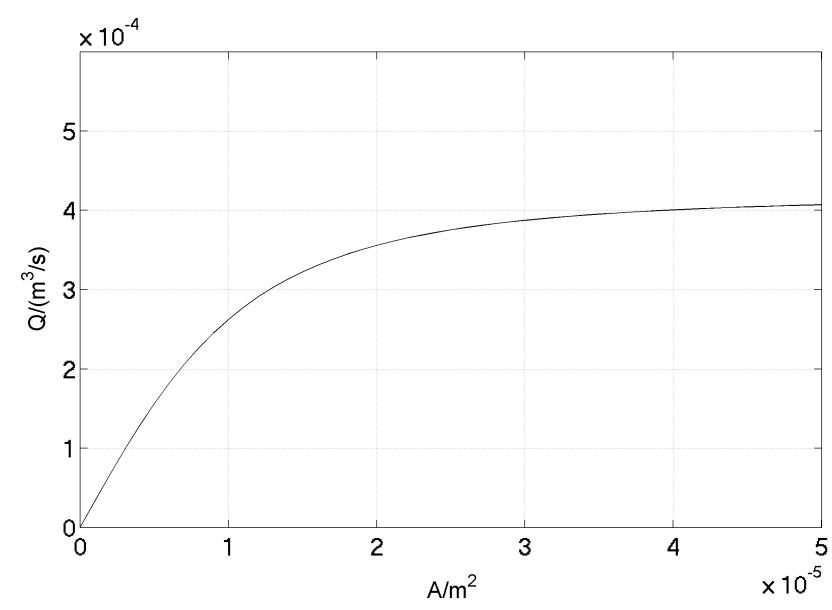

Fig. (7). Orifice flow area - flow curve.

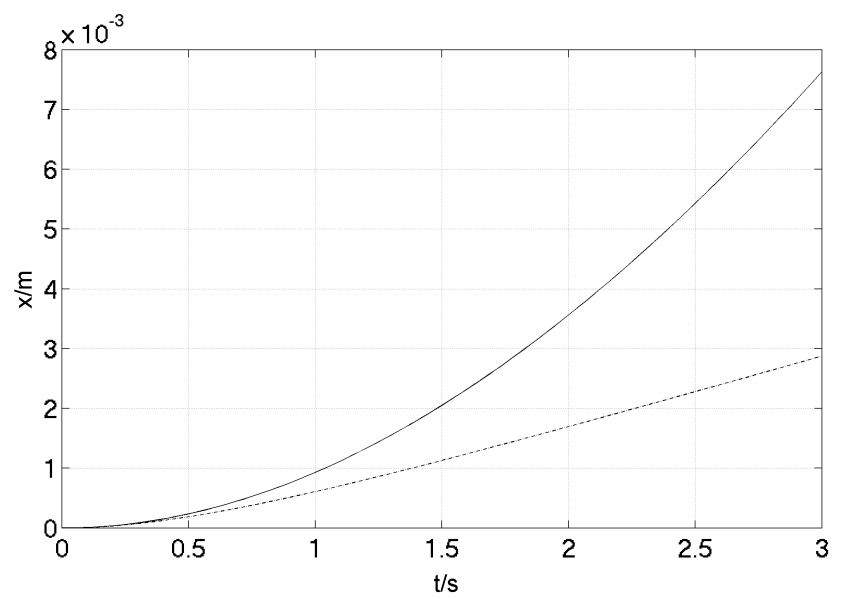

Fig. (8). The SOV's piston displacement curve.

Therefore, in the assembly process, after the FRV has been repaired, the assembly tolerance of spool set and the length tolerance of spring must be controlled strictly.

The four FRV orifices and three adjustable flows are used to regulate the fuel flow rate and the ratio of hot and cold fuel. Because flows through the four orifices will be mixed into one flow before entering FCV, it can be as one orifice to analyze its impact on the flow rate. Fig. (7) shows the flow characteristic curves varying with flow area of orifice; the curves show that with the increase of flow area of orifice, flow rate will also be increased. The smaller the flow area is, the more obvious the impact on flow rate change will be. If the adjustment of orifice's adjustable screw is not correct or changed in service, it will cause an adverse effect on the flow.

\subsection{The Fault Simulation Analysis of Response Time-Out and Refusing To Move}

Control circuit may fail because of electromagnetic failure of solenoid, foreign material or lack of lubrication.
The problem that control flow circuit's response is time-out, which is caused by leakage or lubrication failure, should be firstly considered, as the leakage or lubrication failure may cause the increase of damping. In Fig. (8), the solid line is the displacement of the SOV's piston in normal service for $3 \mathrm{~s}$. Only when the piston displacement exceeds $6 \mathrm{~mm}$ the SOV can be fully opened. The dotted line is the simulation when the fluid damping increases. It can be seen that the piston displacement could not reach to $6 \mathrm{~mm}$ in $3 \mathrm{~s}$, leading to response time-out. The output result is shown in Fig. (9), where the solid line is the output flow change curve in normal service, and dotted line is the flow change curve under fault condition.

When the solenoid meets electrical faults such as shortcircuit and open-circuit or foreign matte in it, it may cause the FRV refuse to work. Fig. (10) shows solenoid's spool displacement in sudden appearance of electrical fault conditions, leading to the FRV not operating normally. The output result is shown in Fig. (11), where the solid line is the output flow change curve in normal service, and dotted line is the flow change curve under fault condition. 


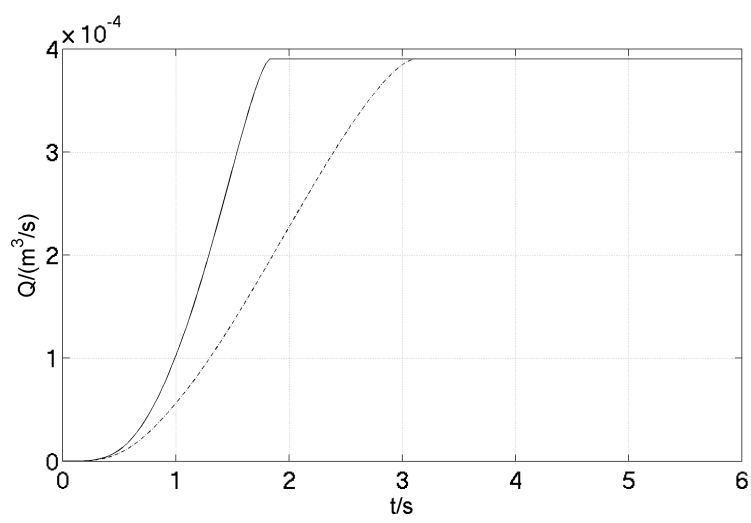

Fig. (9). Shut-off valve action time-out.

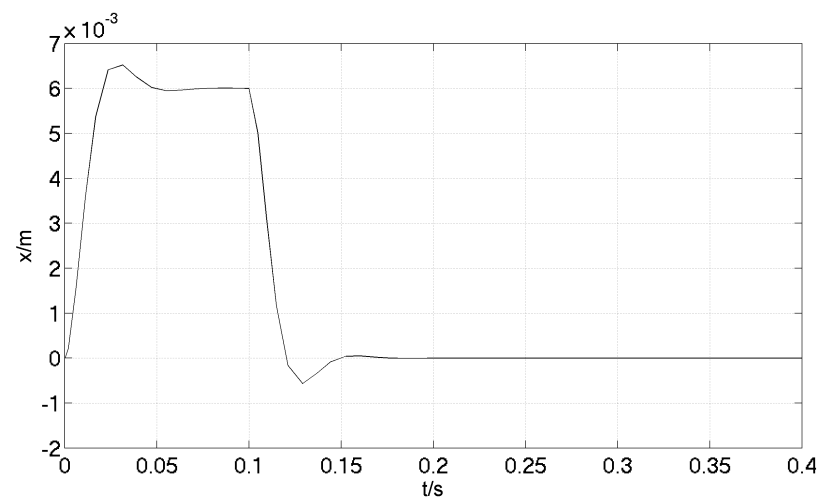

Fig. (10). Variation of solenoid's spool displacement under electrical fault.

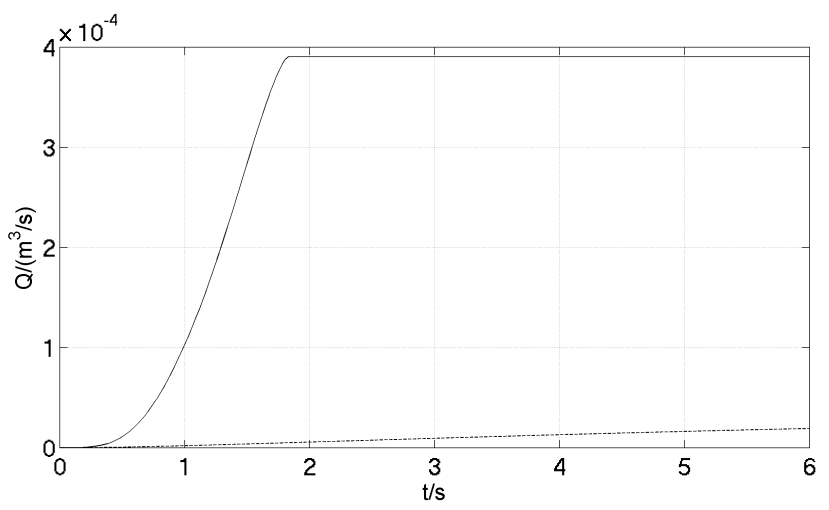

Fig. (11). SOV failure of refusing action.

\section{SUMMARY}

Simulink was utilized to establish the computer simulation model of the FRV, and the fault analysis was taken. It can be seen from the simulation results that the FRV's FCV has a great influence on the stability and accuracy of the flow, and the performance of FCV's spring is of vital importance. When spring is fatigue, its stiffness will be insufficient and length may change, which may cause the exceeded flow rate. Regulation of orifices also has an impact on the flow change, thus attention should also be paid to effective fastening of screws on the orifice after adjustment.
The FRV's refusal to work, flow regulation failure and reaction time-out are the results of leakage or electrical failure. In order to prevent the solenoid failure, which causes the FRV's failure, the solenoid's electrical connection should be regularly checked in case of excessive heat and other abnormality.

\section{CONFLICT OF INTEREST}

The authors confirm that this article content has no conflict of interest. 


\section{ACKNOWLEDGEMENTS}

This work is supported by National Natural Science Foundation of China (Grant No. \#U1233201); Important \& Specific Projects of Civil aviation science and technology project; Tianjin Science and Technology Support Key Project (Grant No. \#11ZCKFGX04000); Fundamental Research Project of the Central Universities (Grant No. \#ZXH2012B002 \& No. \#3122013P005 \& No. \#3122013D002 \& No. \#3122013D006); and China Aviation Industry IUR Cooperative Innovation Engineering Project (Grant No. \#CXY2012MHDX3).

\section{REFERENCES}

[1] L. Hao, and X. Wang, "Aircraft fuel system diagnostic fault detection through expert system," In: Proceedings of the World Congress on Intelligent Control and Automation (WCICA), 2008, pp. 7099-7103.

[2] H. Qu, X. Ding, and T. Wang, "Aeroengine oil fault diagnosis based on D-S evidential theory", Journal of Applied Mechanics and Materials, vol. 141, no. 1, pp 15-20, 2012.

[3] L.M. Bartlett, E.E. Hurdle, and E.M. Kelly, "Integrated system fault diagnostics utilizing digraph and fault tree-based approaches", Journal of Reliability Engineering and System Safety, vol. 94, no. 6, pp. 1107-1115, June 2009.
[4] E. Naderi, N. Meskin, and K. Khorasani, "Nonlinear fault diagnosis of jet engines by using a multiple model-based approach", Proceedings of the ASME Turbo Expo, vol. 1, pp. 63-75, 2011.

[5] N. Sriram, B, Gautam, "Model-based diagnosis of hybrid systems", IEEE Transactions on Systems, Man, and Cybernetics Part A: Systems and Humans, vol. 37, no. 3, pp. 348-361, May 2007.

[6] X. Xu, C. Luo, and Y. Feng, "Analysis of dynamic modeling of aviation heavy oil piston engine fuel delivery system," Journal of Hangkong Dongli Xuebao/Journal of Aerospace Power, vol. 27, no. 4, pp. 846-853, April 2012.

[7] T. Shen, F. Wan, W. Cui, and B. Song, "Application of prognostic and health management technology on aircraft fuel system", In: 2010 Prognostics and System Health Management Conference, PHM'10, 2010.

[8] K. Kim, " Fault diagnosis and prognosis for fuel supply systems in gas turbine engines", Journal of Proceedings of the Institution of Mechanical Engineers, Part C: Journal of Mechanical Engineering Science, vol. 223, no. 3, pp. 757-768, March 2009.

[9] S. Hou, Y. Li, M. Li, and X. Wei, “ Analysis of dynamic modeling of aviation heavy oil piston engine fuel delivery system", J.Tuijin Jishu/Journal of Propulsion Technology, vol. 28, no. 1, pp. 86-91, February 2007.

[10] W. Geng, T. Xu, and Q. Wang, “ Method of sensor fault diagnosis in liquid rocket engine ground testing bed hydrogen providing system based on MSPCA", Journal of Yuhang Xuebao/Journal of Astronautics, vol. 27, no. 6, pp. 1142-1146, 2006

[11] L.C. Jaw, and J.D. Mattingly, "Aircraft Engine Controls: Design, System Analysis, and Health Monitoring," American Institute of Aeronautics \& Astronautics, 2009.

[12] W. Ward, "Aircraft Engine Systems," Component Maintenance Manual with IPL 8910 Series Fuel Return Valve. 2003.

Received: September 16, 2014

(C) Liwen et al.; Licensee Bentham Open.

This is an open access article licensed under the terms of the Creative Commons Attribution Non-Commercial License (http://creativecommons.org/licenses/by-nc/4.0/) which permits unrestricted, non-commercial use, distribution and reproduction in any medium, provided the work is properly cited. 